Copyright 1910. By A.I.E.E.

\title{
THE MODERN OIL SWITCH WITH SPECIAL REFERENCE TO SYSTEMS OF MODERATE VOLTAGE AND \\ LARGE AMPERE CAPACITY
}

BY A. R. CHEYNEY

The oil switch has become a fundamental part of all large generating systems, and so well has it fulfilled its function that not only has it superseded practically all other forms of switches for such service at all voltages, but manufacturers unhesitatingly claim that it can be constructed so as to safely open short circuits under the worst possible conditions in systems of unlimited kilowatt capacities, the only limiting condition, of course, being that the consumer be willing to pay for it.

In spite of this assurance, repeated warnings that the present switches are becoming a source of possible danger in the rapidly growing central station systems of our large cities are being heard, although neither manufacturer nor operator has seemingly thus far placed any absolute safety limit on just how large a system the present switch is entirely capable of protecting.

Switches may be divided into three classes, each class being further sub-divided into extra high voltage, moderate voltage and low voltage. The three main classes are based upon the maximum generating capacity that the switch may reasonably be called upon to interrupt. The classification, therefore, becomes in fact switches for small systems, for systems of moderate capacity, and switches for use in systems of the largest size. So long as the operating man does not object, the rating of this latter type of switch will continue to be for systems of " unlimited capacity," as any experimental evidence to the contrary is at the expense of the operating system itself.

It is further manifest that oil switches may be built to safely 
and continuously carry any current that may be required. The use of the switch as a circuit-breaker is the limiting factor in the case. Every switch thus used must not only be able to safely carry or interrupt the load of its particular section, but it must also be capable of safely and repeatedly interrupting shortcircuits under severe conditions, with the whole capacity of the generating, transmission, and receiving systems behind it.

The switch with which this paper is mostly concerned is the type almost universally used in the large generating systems of our cities, where the voltage usually runs from 13,000 to 6,000 volts per phase, and is manufactured in various sizes, the 2,500 volt switch with a capacity up to about 3,000 amperes, the 15,000 volt switch up to 2,000 amperes, and the 35,000 -volt switch up to 300 amperes rated capacity. Under these conditions the temperature rise in the oil cylinders or tanks is generally kept as low as possible, 28 deg. cent. being sometimes specified.

The switch of both large and small ampere capacity for extra high potential systems seems to have rapidly made a place for itself in the high-tension transmission systems of the country, and to have been extremely satisfactory in most instances. One 60,000 -volt switch, it is claimed, opened twenty-five consecutive short-circuits, with a generating capacity of 10,000 kilowatts, within a space of one-half hour, and although the oil was carbonized to a considerable extent, the switch opened the arc entirely satisfactorily on the last break. In another instance two 60,000 -volt breakers which had been in service for three years have opened several hundred short-circuits, many of them severe, without a change of oil. The generous dimensions of these switches are sufficient to show that the design is amply safe with regard to distances between conductors, the manufacturers claiming that they figure on an oil which has dropped in insulation until it may be broken down from 6,000 to 10,000 volts on a 0.2 -in. gap between needle points. It is impossible in practice, with systems of this nature, to maintain the oil at an exceedingly high insulating value without a great deal of labor and inconvenience, particularly on account of the moisture that is absorbed from the atmosphere. In these switches for high voltage systems, which are now on the market in capacities up to $400 \mathrm{am}-$ peres at 110,000 volts, experience seems to show that a large volume of oil greatly increases the factor of safety. Some manufacturers also claim that in switches of this class a horizontal is superior to a vertical break as the pressure due to the head of 
the oil above the contacts is more effective in preventing the arc from reaching any large dimensions. Switches with a horizontal break are usually made with a thin knife blade in order that it may cut through the oil with the least disturbance. Judging from the written expressions of the users of these high-tension switches, it is evident that for the conditions under which these switches operate they are giving very satisfactory service.

Until the introduction of the steam turbine with its high rotative speeds and correspondingly low self-induction, the present plunger type of switch seemed to fulfill every expectation in moderate voltage systems of large generating capacity. The enormous growth of connected load and, at the same time, the adoption of the turbine as a prime mover, have brought about conditions unforeseen; and not only has the ability of modern switch construction to safely care for the new conditions been questioned, but experimental evidence would lead to the conclusion that either a new form of switch is urgently needed or else a marked change in switchboard construction and station operation.

The high-power switch for 6,000 - to 13,000 -volt service has at all times required careful supervision, constant attention to smaller details of its operating mechanism, and periodic tests, in order to ascertain that it was always ready for service. This, of course, is not unreasonable. Heavy short-circuits, however, have frequently demonstrated the fact at the present time in our large stations no circuit-breaker which has once opened under heavy short-circuit conditions is entirely safe to be put back on the line again without a thorough overhauling of contacts, cleaning up of the switch and its compartments, on account of the large amount of oil which has been blown out by the explosive pressure of the arc, and also the refilling of the switch cylinders. It is frequently necessary to insert an entirely new set of contacts and to file down the rod tips. This whole operation involves a period of at least two hours, and if spare feeders are not available may lead to considerable annoyance, while, in any case, it may involve a temporary disablement of a large and important investment in apparatus.

Changes, such as the substitution of steel for brass pots, the addition in some instances of insulating dashers to assist in keeping the oil within the pot and also to facilitate the breaking of an arc, and improved operating mechanism and contacts, cover practically all the main points that have been improved 
upon, since the introduction of the 8-in. cylinder eight or ten years ago, notwithstanding the enormous increase in maximum short-circuit output of the turbo-generator over that of the enginedriven alternator of equal capacity and the fact that the size of units has increased from $5,000 \mathrm{kw}$. to $20,000 \mathrm{kw}$. The substitution of boiler-iron tanks for wooden tanks and the gravity opening, with a means of obtaining a certain forced oil flow across the contacts on opening the switch, are a few of the changes in another type.

The Committee on High Potential Disturbances of the Association of Edison Illuminating Companies, 1909, notes that several of the larger companies are making use of reactances in connection with their turbines. These are installed either in the neutral leads of the turbo-generator or in the phase leads themselves. The reactances also facilitate parallel operation. A committee of the same body during the previous year suggested a limit of 40,000 kilowatts of installed machinery as a maximum generating installation that could be safely protected by a modern switch. As, in several instances, the switch has caused considerable damage, frank discussion in the line of improvement of the switch design is asked for.

As a matter of record, with $15,000 \mathrm{kw}$. of turbines in service, the latest type of oil switch has been quite recently practically emptied of its oil, the remaining oil being reduced to a state of absolute blackness and the contacts and rods so badly burned that they were unfit for further use without renewing, makes it evident that some change is needed in our present switchboard or switch design.

Modern operation generally calls for the use of a single operating bus-bar for reasons of both reliability and economy. Choke coils to limit the generating capacity in one section of the bus to a value of perhaps $20,000 \mathrm{kw}$., or a capacity slightly above that quoted when the switch was disabled, would seem hardly practical. As the load continues to grow with enormous strides, it would certainly seem that a more powerful type of switch should be found. As far as ascertained, resonance rises of potential due to the opening of an arc in an oil switch are of comparatively rare occurrence. It is natural to suppose that, whatever changes are made, the arc will still be broken under oil.

A few remarks of a general nature on switchboard construction and arrangement may not be out of place. A feeder switch, or 
circuit-breaker includes properly the knife switches separating the switch from the underground cable system, the series transformers, relays, control wiring and the switch itself with its fireproof compartment. It would not, therefore, seem illogical to adopt a type of construction in which all of these parts are relatively close together, instead of being scattered perhaps hundreds of feet apart as is frequently the case. For instance, the series transformer; the relays, the current through the coils of which, incidentally, should also pass through the circuit ammeters of the operating board, and the actuating mechanism of the switch belong together. The cable knife switch should be so placed as to be visible when working on the circuit breaking switch itself-in other words, in the base of the switch compartment. The bus bar knife switch should also be visible to any one working on the selector switches to obviate any chance of mistake in switching, and, furthermore, to protect the operator. This means, then, the bus bar and selector switch compartments must be one, so constructed that every switch section is independent and that the complete demolishing of one switch will not in any way affect either the neighboring switches or the bus bars themselves. This arrangement, mentioned above, will not only greatly reduce the space required for present switchboards, but will assist materially in proper maintenance and repair.

It is possible that it may become good practice where the plant equipment includes two switches in series for each feederone automatic and the other non-automatic-to allow the time element relay to open both switches in order to assist in breaking the arc, although this should not be necessary with a reliable switch. In connection with the use of choke coils the suggestion has been made that these coils be short-circuited by a heavy switch which would be opened by a relay when required. It is doubtful if any switch yet constructed would be quick enough to give the effect desired and on this account, and also on account of simplicity, choke coils, if installed at all, should be so designed as to care for operating conditions without the intervention of an iron core or moving mechanism.

As an illustration of the exceedingly heavy duty required even of a 300-ampere switch on a single feeder cable in the case of a $50,000-\mathrm{kw}$. steam turbine station of 6,000 volts, the instantaneous short-circuit current would amount to $50.000 / \sqrt{3 E}$ $\times 50=240,600$ amperes per phase, or a kilowatt output, assuming a power.factor for the short circuit of 40 per cent, of 50,000 $\times 50 \times 0.40=1,000,000 \mathrm{kw}$. 
A $100,000-\mathrm{kw}$. plant under similar conditions would give an output of $2,000,000 \mathrm{kw}$. It is expecting a great deal of a 300ampere switch to suppose that it could be safely figured on to care for such an enormous amount of energy. Yet the facts remain as stated. There are several modifying conditions, however, which enter into the problem. In the first place, shortcircuits as a rule are not absolute short-circuits, and in this way the number of amperes actually interrupted is probably far less than that calculated. It must also be borne in mind that even if a circuit-breaker on a feeder were provided with an instantaneous relay, the time element of the switch itself is considerable, so that by the time the arc had been opened, the armature reaction of the machines would have, to a certain extent, become effective, thereby dropping the voltage and still further lowering the amperes at the break. If the safety of the switch alone is considered, it would doubtless be expedient to install inverse time element relays in connection with the feeders which would give an exceedingly long time interval in connection with the 100 per cent or more overload setting of the breaker, in order that they might give perhaps a three or four second interval between the occurrence of the short circuit and the opening of the switch. While specific information with regard to the length of time which is required for the armature reaction of alternators to become effective is lacking, there is no doubt that a mean might be drawn between conditions most favorable to the switch and those upon which depend the stability of operation of the main and substation synchronous machinery. Were it not for the possible rise in potential due to the breaking of the arc when the current is perhaps at a maximum instead of at zero point of the wave-which is another fact upon which further light is much needed and upon which the oscillograph without doubt will prove of great assistance in effecting a solution-the operating man would much prefer to have a short circuited cable cut off instantly before the trouble has had time to reach its heaviest proportions or has become severe enough to interfere with the frequency or voltage of the system.

The problem of the oil switch demands the more nearly exact solution of these questions. The protection which might possibly be afforded against the effect of static surges by the aluminum cell arrester might well be considered in this connection. With this protection, it would seem that the advantage lies practically altogether in favor of opening the switch itself 
as quickly as possible, by which it is understood that the greatesi reasonable amount of time should be given by means of the relay to the switch before the latter starts to open the arc without, on the other hand, taking chances of throwing off the synchronous machinery. Under the best of conditions, however, we can but see that the switch is a relatively weak link in a system involving millions of invested capital.

The breaking of a circuit consists of inserting more or less gradually into the circuit a resistance which grows at a variable rate from zero to a maximum. At the moment the switch is leaving the contact, the greater the $C^{2} R$ loss in heating, and especially if the circuit be inductive, the greater the amount of arcing. The rapid falling off in amperes as the resistance is increased by distance, when a considerable amount of metal is vaporized, and by this means the breaking of the arc is considerably hindered, is probably not at first accompanied by any great drop in the heating effect on the oil and the contacts, the $C^{2} R$ loss for a certain length of time being perhaps practically constant. This, in part, is probably the cause of the explosive pressure set up in the cylinder by the oil vapor assisted by the actual displacement of oil by the arc itself. The prolonged arcing is evidently also the cause of the large amount of carbonization which takes place on opening a heavy shortcircuit under oil with the modern switch.

Although there has not been a great deal written upon the exact nature of what takes place when a heavy arc is thus broken, experimental evidence has shown us that the quality of the switch oil will without doubt play a very important part in the switch of the future. The electrostatic stress set up between two charged conductors in a light mineral oil such as is used in switches and transformers, will, under proper conditions, even though no appreciable current is allowed to flow, release considerable quantities of gas without appreciable change in the oil itself, and as this gas is naturally rich in hydrogen, may it not be that the explosive violence of some of our short circuits is due to the combination of this gas and the gas driven off by the heat of the arc with oxygen, possibly of the air? The carbonization which takes place when a heavy short-circuit is broken is sometimes sufficient to make a deposit on settling of $\frac{3}{8}$ of an inch in a 4 -inch column of oil, or a total volumetric proportion of 10 per cent between the amorphous carbon and the clear oil above. The actual sample measured was taken from 
an oil switch cylinder from which two-thirds of the oil was blown out by the violence of the explosion. The physical analysis of the fresh oil (No. 6 transil oil) was as follows:

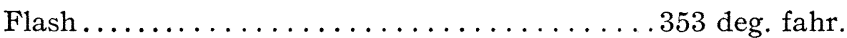

Burn..........................402 " "

Gravity at $60 \mathrm{deg}$ fahr.............. $31.4 \mathrm{~B}$.

As regard acidity, the oil was very nearly neutral, 0.09 per cent of potassium hydrate being required to neutralize same. There was no organic matter present. Various tests were made to ascertain the specific resistance and the dielectric strength of the above oil under the following conditions; first, the new oil; second, the blackened oil as taken from the switch; third, the clear oil after filtering off the carbonization. Careful tests were made under different conditions such as the sparking distance between needle points, between flat disks, between two $\frac{3}{4}$-in. balls, between a needle point and a disk, between a needle point and ball, etc. In some of the tests it seemed that the filtered oil after heavy carbonization showed an increase in specific resistance over the new oil. The dielectric strength also seemed materially increased after carbonization and filtering. The carbonized oil as taken from the switch showed a specific resistance of only one-fourth that of the new oil or of only one-eighth the resistance per $\mathrm{cu} . \mathrm{cm}$. of the oil after removing the carbonized particles by filtration, although another series of tests of other samples of the same oils failed to confirm the above figures; still there was a marked difference between the samples, although any increase in specific resistance or in dielectric strength failed to materialize except in one instance. The following figures, however, which are abstracted from the second series of tests represent the sparking distance between two $\frac{3}{4}$-in. balls at approximately $22.5 \mathrm{deg}$. cent. under a depth of oil of $2 \frac{1}{4} \mathrm{in}$.

\begin{tabular}{ccc} 
Sample & Gap & Volts \\
\hline No. 1-Blackened oil (filtered) ........ & $0.15^{\prime \prime}$ & 12,000 \\
No. 2-New oil................. & $0.20^{\prime \prime}$ & 29,000 \\
& $0.15^{\prime \prime}$ & 12,000 \\
& & 29,500
\end{tabular}

The following figures, representing the break-down point in inches at 30,000 volts pressure, as measured by an electrostatic voltmeter, checked by needle points, are also given: 


\begin{tabular}{|c|c|c|c|c|}
\hline Sample & $\begin{array}{l}\text { Needle } \\
\text { points }\end{array}$ & $\begin{array}{c}\text { Needle } \\
\text { and } \\
\frac{3}{4} \text {-in. disk }\end{array}$ & $\begin{array}{c}\frac{3}{4} \text {-in. Ball } \\
\text { and } \\
\frac{3}{4} \text {-in. disk }\end{array}$ & $\begin{array}{l}\text { Between } \\
\frac{3}{4} \text {-in. balls }\end{array}$ \\
\hline & 111. & in. & in. & in. \\
\hline No. 1-Blackened oil..... & 0.635 & 0.610 & 0.320 & 0.220 \\
\hline $\begin{array}{r}\text { Blackened oil fil- } \\
\text { tered } \ldots \ldots \ldots\end{array}$ & 0.5 & & 0.250 & 0.190 \\
\hline No. 2-Blackened oil..... & 0.420 & 0.675 & 0.615 & 0.310 \\
\hline $\begin{array}{c}\text { Blackened oil fil- } \\
\text { tered } \ldots \ldots \ldots\end{array}$ & 0.300 & 0.600 & 0.290 & 0.185 \\
\hline No. 3 -New oil .......... & 0.575 & 0.755 & 0.502 & 0.665 \\
\hline
\end{tabular}

Temperatures in the above table all 26.5 degrees $\mathrm{C}$.

All distances were measured by michrometer, the voltage adjustment being secured by finely adjusted resistances in the primary of a 40,000-volt testing transformer. As this may have introduced possible error due to change in wave form the figures are given as being perhaps at best, only approximately correct.*

Whether or not the changes in an oil produced by carbonization under heavy arcing improves or reduces the values of the remaining filtered oil for use in oil switches, it seems quite urgent that oil for switch purposes be chosen with great care, and manufacturers should make public satisfactory specifications to cover such oils and the testing of the same. It is by no means certain, as is frequently claimed, that a good transformer oil will make a good switch oil. Carbonization under heavy arcing is undeniably unavoidable. The study, however, of the physical and chemical nature of the actual conditions existing while the arc is being drawn through the oil with regard to the oil itself may lead to valuable conclusions that will somewhat strengthen the present oil switch situation.

It may be necessary to reduce the carbon content of the oil or possibly the hydrogen and more volatile components, even perhaps at the expense of changing the viscosity. Careful specifications will be welcomed by operating companies.

The severity of the arcing is naturally dependent upon the pressure of the oil surrounding the arc, the temperature of the

* Other interesting figures in connection with the same kind of investigation are given in a paper read before the Manchester Local Section of the Institution of Electrical Engineers, by W. Pollard Digby, and D. B. Mellis, of which an abstract appears in the London Electrician, April 1, 1910. Important papers on this subject by Messrs. Skinner, Kintner, Steinmetz and others have appeared in the technical press. 
oil and contacts, the velocity of switch opening, and, of course, by the ampere density at the point of break. The amount of vaporization of the contacts should be reduced to a minimum by properly proportioning the switch parts, by artificial circulation of the oil across the contacts as they are separated, and by increasing the velocity at the break to as high a degree as is possible. Severe arcing, even under oil, may without doubt be sufficient to set up heavy oscillations in a large underground system and, although much has been written upon the advisability of retarding the switch in its action, it frequently seems very advisable to have an absolute short-circuit broken as quickly as the switch will open it, the limiting factor being the reliability of the switch itself.

The oscillograph in the near future will also doubtless add to our knowledge of the conditions existing in a severe arc closely confined, as in the case of an oil-switch cylinder under pressure. As stated above there seems to be considerable difference in opinion among engineers with regard to whether the opening of a switch should be in a horizontal or vertical direction. While many of the high-tension switches in the West use a horizontal break, depending upon a large volume of oil and a narrow knife blade for contacts, practically all of the high-power switches of moderate voltage have a vertical throw, in some cases opening by gravity, which has the advantage that the switch can never accidentally fall into contact; while in other types the switch opens upwards.

There has been developed, although apparently it has never yet been introduced as a commercial article, an oil-switch in which the oil is at all times under pressure which is maintained by a compressed air system-a pressure line of perhaps 150 or $200 \mathrm{lb}$. caring for a number of switches, and a gravity or return line returning the discharged oil to the system. This principle seems to be exceedingly promising insofar as breaking the arc is concerned, the switch cylinders being either always full of oil under pressure, the opening of the contacts allowing a heavy stream of oil to be forced directly across the arc and through the hollow contact to atmospheric pressure, or as in another case, where the tripping coil opens an oil valve which admits large quantities of fresh oil under pressure to come into direct contact with the heated terminal directly at the base of the arc. It is undeniable that the mechanical squeezing out of the arc is what we need. 
The forcing of considerable streams of cooled fresh oil across the contact face to the atmosphere, thereby eliminating all carbonization and gasification from the oil switch itself, gives a pleasing prospect of what the future may have in store. The breaking of a heavy arc by the weight of a nine- or ten-inch column of oil, especially in small or confined areas is going to be somewhat of a doubtful matter especially as the sizes of operating systems increase.

Another matter which should be carefully considered in connection with the vertical cylinder oil switch is the magnetic repulsion between the oil switch cylinders at times of heavy short circuits. Insulator bases are required, of great mechanical strength, to safely withstand this unusual strain which is perhaps similar in its nature to that which causes the opening of high tension switches under similar conditions, and it may be perhaps that broken base insulators may be traced partly to this cause.

In the matter of oil-switch contacts, practically every form imaginable has been tried particularly in the smaller switches. It need only be mentioned, therefore, that there seems a strong tendency to rely upon the cooling effect of the oil and the large radiating surface of the pot or oil tank to carry off the heat from contacts which in air would run exceedingly warm. An oil switch contact should on account of the very nature of the insulating medium be of at least as large proportions as a similar current carrying contact for use in the air; especially so since carbonization, sedimentation, moisture and other causes may interfere with the contact; and, above all, because it is practically out of sight at all times.

Switches of the more powerful types are generally sufficiently provided as to contact area, but there are certain switches of high current carrying capacity designed for mounting on marble switchboards, for hand or solenoid operation in which the contact surface is naturally too small. The switch, including the oil and the oil tank itself, run exceedingly warm with the contacts most carefully adjusted. This seems a mistake and should never exist in any oil-switch which is placed in a position of responsibility. The temperature of such a switch contact cannot be noticed by handling as can that of a low tension knife switch, so that the greater amcunt of power per ampere precludes any cutting down of contact area if at the expense of a rise in temperature over normal conditions. Information as to the increase of conductivity of a contact due to increase of pressure is not very plentiful for contacts under oil. 
The operating mechanism of large oil-switches can be of the pneumatic, hydraulic, solenoid or motor type. The pneumatic control seems especially adapted for switches of extra high voltage and of certain types, although these switches are very frequently solenoid operated. In the switches of systems of large ampere capacity, the choice between solenoid and motor types of mechanism seems an open one. Both types are fulfilling their proper functions in a satisfactory manner, so far as can be ascertained.

The method of control and the wiring of the same vary with conditions. Generally, the pilot switch that stands in the " off " position and inclining toward the contact last in use is adopted, principally for reasons of wiring connection. The style of pilot switch which remains in contact until thrown into another position is a most excellent switch, and for some reasons, especially in synchronizing, is preferable to the open type, if connections allow of its use. Certain switchboard designers prefer the pull-button switch where all the contacts are on the under side of the operating table, thus precluding any possible switch action due to the dropping of any conducting body upon the operating table, and thus operating switches at inopportune times.

Generally, the simplest switch seems the best, and with a switchboard comprised of plain knife switches so that the operator can always see that his contact conditions are satisfactory, the limit of simplicity has been approached. Synchronizing by pulling out a switch seems perhaps the least bit awkward as contrasted with throwing it in. Not only is it advisable as stated below that the circuit ammeters shall indicate any open circuit condition of the relay coils, but it is advisable if possible that the control wiring be so installed that the operator is informed by his pilot lamps in case of any failure or open-circuit condition in actuating current supply through the relay or the pilot switch itself.

Standardization in the case of oil switches has been made somewhat difficult, so that an excessive number of spare parts must at times be kept in stock. It seems unfortunate that several types of motors, for instance, all of the same general size, speed, and voltage shall be necessary, frequently perhaps on account of the changes of the distance between shaft center and base or a slight change in the base clamping arrangement. The same, of course, applies to motors on governors, main field 
rheostats, field-break switches, etc. In laying out a new station the designer should see that the number of types of auxiliary motors are reduced to a minimum, so that instead of six or eight or even more types, two or three will fulfill the conditions.

The interlocking of high power switches has not generally seemed advisable up to the present date excepting through the control wiring scheme. It is, of course, always advisable that this be so arranged that the synchronizing plug or switch shall carry the actuating current of the selector oil-switch so that it will be impossible for the operator to synchronize a machine with one operating bus and throw it on the other. Interlocking is furthermore undesirable in many instances as the buses are frequently doubled up for various operating reasons, this arrangement affording a very flexible means of caring for the every day happenings of the central station system. In a system in which each generator and feeder consists of a main circuit-breaker and two selector switches any set of selector switches may be utilized for tying together the buses, although the generator switches will generally be used.

Interlocking in the smaller types of switches designed for mounting directly on a switchboard panel or otherwise has not as a rule seemed advisable. The great tendency toward cheapness of production has actually interfered with proper design of some of the smaller switches to such an extent that it is suggested that all unnecessary complications should be avoided and the money invested placed in the switch itself, providing only a first class yet simple operating mechanism. The smaller type of switch may be hand-solenoid-or motor-operated. When used as a circuit-breaker it must be installed in systems within the limits of capacity as given by the manufacturers. Its use on systems of the heavier class is not advisable unless in substation installations when it may be safely used as a single throw device for a bus selector switch, provided that a heavy type of switch is used as a circuit breaker. This lighter switch finds a very abundant field on account of its relatively low cost, especially on voltages from 2,400 to 13,000 . It is frequently used as a remote control switch, as a manhole or pole-type switch, and on the outgoing 2,400-volt wires from alternating-current transformer substations. There is lacking, up to the present time, any adequate time element device for this useful switch, so that unless special relays are used on the switchboard, circuit-breaker setting by means of the tripping coils generally means the opening 
of every switch in the series on short circuit, which is extremely objectionable. The usual practice, therefore, in this connection, is to solidly block everything possible and to remove all blocks only at the time of known danger or when switching. This at best is a dangerous practice and it is hoped that at a near date some satisfactory time element device will be furnished with all such switches for station use, as this will not only make possible selective setting of the various switches, but will possibly protect the switch itself.

In the alternating-current substations of a generating system of any considerable size the double throw form of polyphase switch in which both of the main bus bars, for instance, of the substation enter one switch, is generally inadvisable, especially in the switches of large ampere capacity and one self-contained oil tank such as is being furnished at the present day. It is preferable to install two first class oil switches, one for each bus in such a situation that repairs to switches and regular overhauling can be carried on safely and all chances of trouble between buses, and also the necessity of lowering an oil tank with very small clearances while the switch is alive, is practically entirely done away with. This double-throw type of oil-switch in which the dimensions are reduced to a minimum and the design is influenced to a large extent by commercial conditions, is especially dangerous if used as a circuit breaker. The operating mechanism, furthermore, of many of the switches of this type is very frequently of too light a nature to be consistent with the responsibility thrown upon the switch. Further defects which are brought about by the necessity for economy of space in the same type are weak insulators, and weak insulator support, also the difficulty of aligning the contacts and the contact yoke and of keeping them in proper alignment. Loose insulators, loose studs, and leaking tanks are of very frequent occurrence with some types of switches.

If light duty switches are installed in situations where they can be called upon to open short-circuits beyond their rated capacity in kilowatts, the oil is badly carbonized, the tanks are liable to become damaged, the contacts burned excessively, and the switch emptied of its oil if not actually short circuited. The oil tank for these light duty switches should be given an ample margin of security and purchasers of switches, particularly those which are to be used on systems of large size even though they are not to open exceedingly heavy arcs should 
specify tanks of heavy sheet metal properly riveted and absolutely oil tight. A great deal of trouble has been experienced through leaking of switch tanks in which, mainly for reasons of cost, the weight of the metal has been reduced until the tank itself is much inferior to that of several years ago. A one-eighth inch boiler plate tank, properly riveted is superior in every way to the light weight tanks now so well known. These latter remarks apply particularly to switches for use on switchboard panels. There are certain occasions when commercial conditions step in and a switch is desired at a minimum of cost, even at the expense of a certain degree of security. The operating switchboard of any main or substation, however, is not a location where security can in any way be dispensed with.

There is urgently needed a new type of oil-switch of the cheapest form, preferably of the single-pole type, which shall be automatic in case of predetermined overloads, and which shall be capable of being installed in place of present line boxes on overhead 2,400-volt distribution lines. There is a wide field for the introduction of just the right switch in this connection. At the present time, the market offers no satisfactory device. As these switches could be made in enormous numbers and as the design may be made so that the factor of safety excepting only the matter of insulation, is not exceedingly high, it would seem that it should be possible to manufacture at wholesale such a device that would in a measure compete, even in cost, with the present enclosed fuses and line or manhole cut-outs.

Experience has demonstrated that constant vigilance is necessary with regard to every part of a generating system if service conditions are to be maintained at the highest point of reliability. Especially so is this true of the oil-switch in large systems. Certain defects can be noticed by visual inspection; others require the operation of the switch one or more times, while the inspector closely watches the mechanism and tanks. Still others can only be found by actually taking the switch apart and reassembling it. The inspection necessary, therefore, covers the knife switches, the insulators and contacts, oil-switch mechanism, tanks, rods, base insulators and compartment. To best accomplish this, the work of switch inspection may be sub-divided as follows:

1. Daily inspection of mechanism, tightening up of possible loose nuts, etc., general cleaning of switch. This covers all that can be observed with a reasonable amount of attention while the 
switch is in service, and is given every switch whether carrying current or " dead."

2. Weekly inspection, covering the operation of the switch from four to six times to observe clutch conditions, tripping coils or contacts, open-circuits in wiring, loose parts, bolts, nuts, etc. This test also insures the switch being securely bolted down to its compartment. All doors are taken off or swung open, and tanks, rods, yokes, etc., examined leaky oil tanks cleaned up and any dirty base insulators cleaned off. This latter inspection has frequently located broken base insulators, insulators loose in their iron mountings, loose bolts securing base insulators, loose yokes and wooden shafts, and on one occasion a yoke and set of rods which had actually become disengaged from its clamp on the vertical wooden rod and fallen into the closed position, thereby closing one phase of the switch absolutely without the operators' knowledge. Defective alignment of cylinders, particularly in the case of the older type of switches, and improper switch action are also thus located. This inspection also locates leaky oil tanks, defective cable connections and terminal insulation.

3. Once a year every switch is completely taken down, each part cleaned and oiled, contacts brightened, supplied with fresh oil, and any minor defects that may have crept in are remedied as far as possible.

These three inspections have been found to cover fairly well the operation of the oil-switch in service. The whole of the work outside of the inspection itself is cared for by one man, excepting that the annual overhauling makes it necessary to add one helper to the force. This is in a plant of some 90 high-power switches.

The yearly inspection has discovered at times defects of a very serious nature which would not have otherwise been 1ocated, excepting through the failure of the switch mechanism to operate in service, and also troubles with the switch cylinders, rods or contacts. It is desirable that this systematic inspection be recorded, a separate card being used for every switch on which the various defects are noted. The main purpose, however, as stated above, is that the switches may be in working condition at all times both as to mechanism and the switch itself. Failures to operate when called for, defective contacts, low or defective oil, loose parts within cylinders, defective rod tips, or broken insulators may, any one of them be 
the means at a most inconvenient time of causing trouble. Further records of switch condition besides the details given from the above cards are obtained by grouping the various defects in order that the weak points of the switch may constantly be kept in mind. The number of times the switch is thrown under inspection exceeds in all probability the times that it is actually used in service and has a tendency to cause a certain amount of switch trouble itself by loosening the bolts and con-

Type H Switch Record-1909

Minor adjustments not noted

\begin{tabular}{|c|c|c|c|c|}
\hline & $\begin{array}{l}\text { In } \\
\text { service }\end{array}$ & $\begin{array}{l}\text { Weekly } \\
\text { test }\end{array}$ & $\begin{array}{l}\text { Yearly } \\
\text { overhaul }\end{array}$ & Total \\
\hline Failed to open $\ldots \ldots \ldots \ldots \ldots \ldots$ & 0 & 0 & 0 & 0 \\
\hline Failed to close .............. & 6 & 10 & 0 & 16 \\
\hline Pumped $\ldots \ldots \ldots \ldots \ldots \ldots \ldots$ & 0 & 5 & 13 & 18 \\
\hline Oil renewals . . . . . . . . . . & 7 & 0 & 81 & 88 \\
\hline Oil thrown on short-circuit ....... & 7 & 0 & 0 & 7 \\
\hline Contacts renewed $\ldots \ldots \ldots \ldots \ldots$ & 7 & 0 & 13 & 20 \\
\hline Base insulator loose or broken.... & 0 & 19 & 9 & 28 \\
\hline Failure to open short-circuit...... & 0 & 0 & 0 & 0 \\
\hline Defective contact at brushes.... & 0 & 0 & 12 & 12 \\
\hline Broken castings, bearings, etc..... & 0 & 0 & 5 & 5 \\
\hline Bent crank shafts............. & 0 & 0 & 1 & 1 \\
\hline $\begin{array}{l}\text { Clutch, trip coil and control finger } \\
\text { troubles } \ldots \ldots \ldots \ldots \ldots \ldots \ldots\end{array}$ & 0 & 35 & 2 & 37 \\
\hline Friction in mechanism.......... & 0 & 0 & 27 & 27 \\
\hline Troubles with compartments..... & 0 & 0 & 2 & 2 \\
\hline Closed accidentally ............ & 0 & 0 & 0 & 0 \\
\hline Opened accidentally $\ldots \ldots \ldots \ldots$ & 0 & 0 & 0 & 0 \\
\hline Switches operated, times........ & & & & 35,000 \\
\hline Short-circuits opened $\ldots \ldots \ldots \ldots$ & 12 & 0 & 0 & 12 \\
\hline
\end{tabular}

tacts. It, however, is the only means available whereby the switch action may be entirely depended upon.

The daily inspection thus eliminates the minor troubles apparent to a trained observer; the weekly inspection makes it possible to practically eliminate all external troubles in the switch compartments and in the mechanism, and especially failures to operate when called upon, whether due to open tripping coils, defective clutch coils or otherwise, and practically insures the switch against trouble due to pumping; while the 
yearly inspection cleans up the switch as a whole, making it possible to start a new year with switches fresh and complete from top to bottom.

The actual expense for material in switch maintenance is probably equal to the labor item. The results obtained in a year's service, including operation and inspection of some 90 switches, subdivided into trouble of the mechanism and those of the switch proper are shown in the foregoing table.

In conclusion it may be briefly stated that the present state of oil-switch development, particularly described above, with especial regard to its continued use in the large installations of the future, has not given the operating man quite the same vision of perfect security and unlimited capacity as he would desire. A more powerful switch is seriously needed, a switch which will stand up in continuous service for at least a year without the necessity for overhauling every time a short-circuit is opened. It would not seem unreasonable to wish for this condition in any piece of machinery; and without doubt the oil-switch will be brought up to the standard desired when the operating companies and the manufacturers get sufficiently tlose together. The use of oil in the future switch seems assured. The problem is the right way to use it. From the standpoint of the present enormous and growing investments that are being protected by the device, and with a clear knowledge of the result of failure, there is no doubt that between the designer and the user and with perhaps the assistance of the physicist and chemist that the problem will be readily solved, when once its real importance is fully comprehended. 